OPEN ACCESS

Edited by:

Jinghui Fang,

Yellow Sea Fisheries Research Institute (CAFS), China

Reviewed by:

Simon Jones,

Department of Fisheries and Oceans,

Canada

Sussie Dalvin

Norwegian Institute of Marine Research (IMR), Norway

Shawn M. C. Robinson,

St. Andrews Biological Station

(SABS), Canada

*Correspondence:

Lone S. Jevne

lone.s.jevne@gmail.com

Specialty section:

This article was submitted to

Marine Fisheries, Aquaculture and Living Resources,

a section of the journal

Frontiers in Marine Science

Received: 12 May 2020

Accepted: 11 August 2020 Published: 01 September 2020

Citation:

Jevne LS, Øvrelid MS,

Hagemann A, Bloecher N, Steinhovden KB, Båtnes AS, Olsen Y and Reitan KI (2020) Biofouling on Salmon Pen Nets and Cleaner Fish Shelters Does Not Harbor Planktonic

Stages of Sea Lice.

Front. Mar. Sci. 7:727.

doi: 10.3389/fmars.2020.00727

\section{Biofouling on Salmon Pen Nets and Cleaner Fish Shelters Does Not Harbor Planktonic Stages of Sea Lice}

\author{
Lone S. Jevne ${ }^{*}$, Margrete S. Øvrelid ${ }^{1}$, Andreas Hagemann², Nina Bloecher², \\ Kristine B. Steinhovden ${ }^{2}$, Anna S. Båtnes ${ }^{1}$, Yngvar Olsen ${ }^{1}$ and Kjell I. Reitan ${ }^{1}$ \\ ${ }^{1}$ Department of Biology, Norwegian University of Science and Technology (NTNU), Trondheim, Norway, ${ }^{2}$ SINTEF Ocean, \\ Trondheim, Norway
}

The objective of the current study was to determine the extent to which planktonic sea lice (Lepeophtheirus salmonis Krøyer, 1838 and Caligus elongatus Nordmann, 1832) were present in the biofouling on open-sea net pens used for commercial rearing of Atlantic salmon (Salmo salar L.), and to assess if biofouling organisms on nets act as barriers similar to salmon lice skirts. We have examined two possible interactions of biofouling and planktonic sea lice, the first was if biofouling could function as a microhabitat for planktonic sea lice, with resuspension of sea lice during net cleaning operations. The second interaction was if biofouling may cause a retaining effect on the transport of planktonic stages out of the net pen. These interactions were investigated at different commercial salmon farms. With only one sea louse found among the biofouling on nets and cleaner fish shelters, we found no indication that sea lice utilized biofouling as a reservoir. This was further supported by the lack of impact on the proportion of samples with sea lice and the average density of sea lice in the water following the release of biofouling material during in situ net cleaning. Furthermore, the presence of biofouling had no effect on the proportion of samples with sea lice or the average density of planktonic sea lice in the net pens. The presence of a lice skirt resulted, however, in a significantly higher proportion of samples with planktonic sea lice inside the net pen in one of the two sites utilizing lice skirts. The results of our study suggested that the presence of biofouling has no influence on the average density and proportion of samples with planktonic stages of sea lice and that planktonic sea lice do not inhabit biofouling.

Keywords: sea lice, biofouling, Lepeophtheirus salmonis, Caligus elongatus, lice skirts, sea cage, net pen

\section{INTRODUCTION}

The ectoparasitic salmon louse (Lepeophtheirus salmonis, Krøyer, 1837) continues to constitute major problems for the Norwegian Atlantic salmon (Salmo salar L., Linnaeus, 1758) aquaculture industry, affecting fish health and the economy of salmon farming, while causing public concerns (Costello, 2006; Liu and Bjelland, 2014). Costs of salmon lice control were estimated at US $\$ 436$

Abbreviations: $\mathrm{BCa}$, bias-correlated and accelerated; OR, odds ratio. 
million in 2011 (Abolofia et al., 2017) and newer estimates are even higher (US\$550 million, Iversen et al., 2017).

Caligus elongatus (von Nordmann, 1832) is a second species of sea louse that commonly infests salmon in the northern Atlantic (Pike and Wadsworth, 1999; Johnson et al., 2004; Boxaspen, 2006). Hereafter, the term 'sea lice' refers to both species. The salmon louse embryos hatch directly from the egg strings while still attached to the female (Schram, 2000). The life cycles of both species begin with three planktonic larval stages, of which the copepodite, which follow the two nauplius stages, is the infestive stage (Boxaspen, 2006). The planktonic stages of sea lice are naturally transported with the water currents for long distances in the upper mixed water layer, which enables dispersion between adjacent farms (Asplin et al., 2014; Salama et al., 2016). The planktonic larval stages are small, and the larvae have limited swimming capacity; they perform vertical migrations that can optimize their chances of encountering a host. Planktonic larvae are positively phototactic, thus staying in the upper water masses under conditions of low water mixing (Bron et al., 1993; Heuch et al., 1995; Nordi et al., 2016). Nauplii have been shown to prefer higher temperatures, that optimize and accelerate development time to the copepodite stage (Johnson and Albright, 1991; Pike et al., 2006; á Norði et al., 2015), but have also been shown to aggregate underneath thermoclines if the upper water layer is $>12^{\circ} \mathrm{C}$ (Crosbie et al., 2020). Both nauplii and copepodites of salmon lice avoid low salinities and will aggregate at or under the halocline, if present (Bricknell et al., 2006; Crosbie et al., 2019). The infestive stage needs to find a host before it exhaust the energy reserves from the yolk, because salmon lice do not feed until they attach to a salmon (Piasecki and MacKinnon, 1995; Tucker et al., 2000).

To monitor the level of infestation of salmon lice, and thus the infestation pressure in salmon farms in Norway, the number of lice must be registered on a minimum of 10 fish per net pen (Forskrift om lakselusbekjempelse, 2020a; Thorvaldsen et al., 2019). The farmer must ensure that the mean number of adult female lice per salmon does not exceed 0.5 , although during spring, the limit is further lowered to 0.2 in order to protect the migrating wild salmon smolt (Forskrift om lakselusbekjempelse, 2020b).

The target of many preventive measures against salmon louse infestation is to effectively hinder the copepodites in the surrounding water from reaching the salmon maintained in open net pens. One measure is to cover the net pens with tarpaulins (e.g., lice skirt, snorkel cages, Stien et al., 2016, 2018; Oppedal et al., 2017; Wright et al., 2017), which are generally installed around the upper 5 or $10 \mathrm{~m}$ parts of the net pen (Stien et al., 2018) and can restrict the copepodites from entering the net pen. Planktonic lice are most abundant in the upper water layer (Heuch et al., 1995; Hevrøy et al., 2003), but have also been found down at a depth of $30 \mathrm{~m}$ (Nelson et al., 2018). A considerable amount of literature has been published on the preventative effect of lice skirts and snorkel technologies, and these studies have suggested that skirts can effectively reduce the number of lice on the salmon (Stien et al., 2016, 2018; Oppedal et al., 2017; Wright et al., 2017). Lice skirts thus aims to have a shielding effect, reducing the copepodites entering the net pen. One of the concerns regarding the use of lice skirts is that it can reduce the horizontal flow inside a net pen, which may result in a reduction of water exchange (Frank et al., 2015) and thus lower oxygen levels (Stien et al., 2012).

Reduction of water exchange in net pens may also be caused by biofouling of the net by macro-algae and marine invertebrate organisms such as mussels, ascidians and hydroids (Gormican, 1989; Delauney et al., 2010; Fitridge et al., 2012). By reducing the exchange between surrounding water (Gormican, 1989; Swift et al., 2006; Bi et al., 2018), both lice skirts and biofouling may increase retention times of planktonic sea lice inside the net pen, thus increasing infestation risk. Increased levels of planktonic sea lice on the inside of net pens with dense biofouling growth have been observed (Costelloe et al., 1996). Lice skirts and dense biofouling might therefore also have a retaining effect on the planktonic sea lice exiting the net pen.

It has been suggested that sea lice larvae may have a mechanism to stay close to a salmon farm (Nelson et al., 2018), and that they may utilize biofouling as a microhabitat to maintain their position close to the salmon farms (Floerl et al., 2016) or alternatively, they may be passively transported into the biofouling. Studies have shown salmon sites to be a source of salmon louse nauplii as nauplii have been found in the samples taken downstream of a net pen when no nauplii were found in samples taken upstream (Nordi et al., 2016). The retention of nauplii produced inside of a net pen could lead to a higher internal infestation pressure than expected for that net pen or salmon site if the nauplii are given time to develop into copepodites. A higher proportion of infestations from internal sources compared to external sources of planktonic sea lice might require a new mindset when managing salmon lice.

If sea lice larvae inhabit the biofouling communities, this may not be limited to the biofouling on the net but may also include other fouled structures, such as moorings and cleaner fish shelters, that are placed inside the net pens as a refuge for cleaner fish (Imsland et al., 2015). The most common cleaner fish species used in the salmon industry today are lumpfish (Cyclopterus lumpus Linnaeus, 1758) and wrasse species (Labridae spp.), which are co-cultured with the salmon as biological sea lice control agents (Powell et al., 2018). The natural diet of lumpfish and wrasse includes biofouling organisms, and they can therefore feed on biofouling of the net pens (Deady et al., 1995; Kvenseth, 1996; Imsland et al., 2015; Eliasen et al., 2018). Salmon farmers therefore aspire to keep nets free of biofouling at all times in order to increase the delousing efficacy of the cleaner fish (Bannister et al., 2019). The nets are therefore either regularly changed or cleaned. In Norway, net cleaning by in situ pressure washing are undertaken as often as every 14 days during peak biofouling seasons (July-November; Guenther et al., 2009; Bannister et al., 2019). During cleaning, the biofouling community are removed from the net and released into the water (Bannister et al., 2019). If net biofouling harbors planktonic sea lice stages, net cleaning could cause resuspension of louse larvae, which could spread to neighboring net pens and hence increase infestation risks on-site. Preventive measures could be developed if there are found indications of sea lice dwelling in biofouling, and thus investigating this hypothesis is highly relevant. 


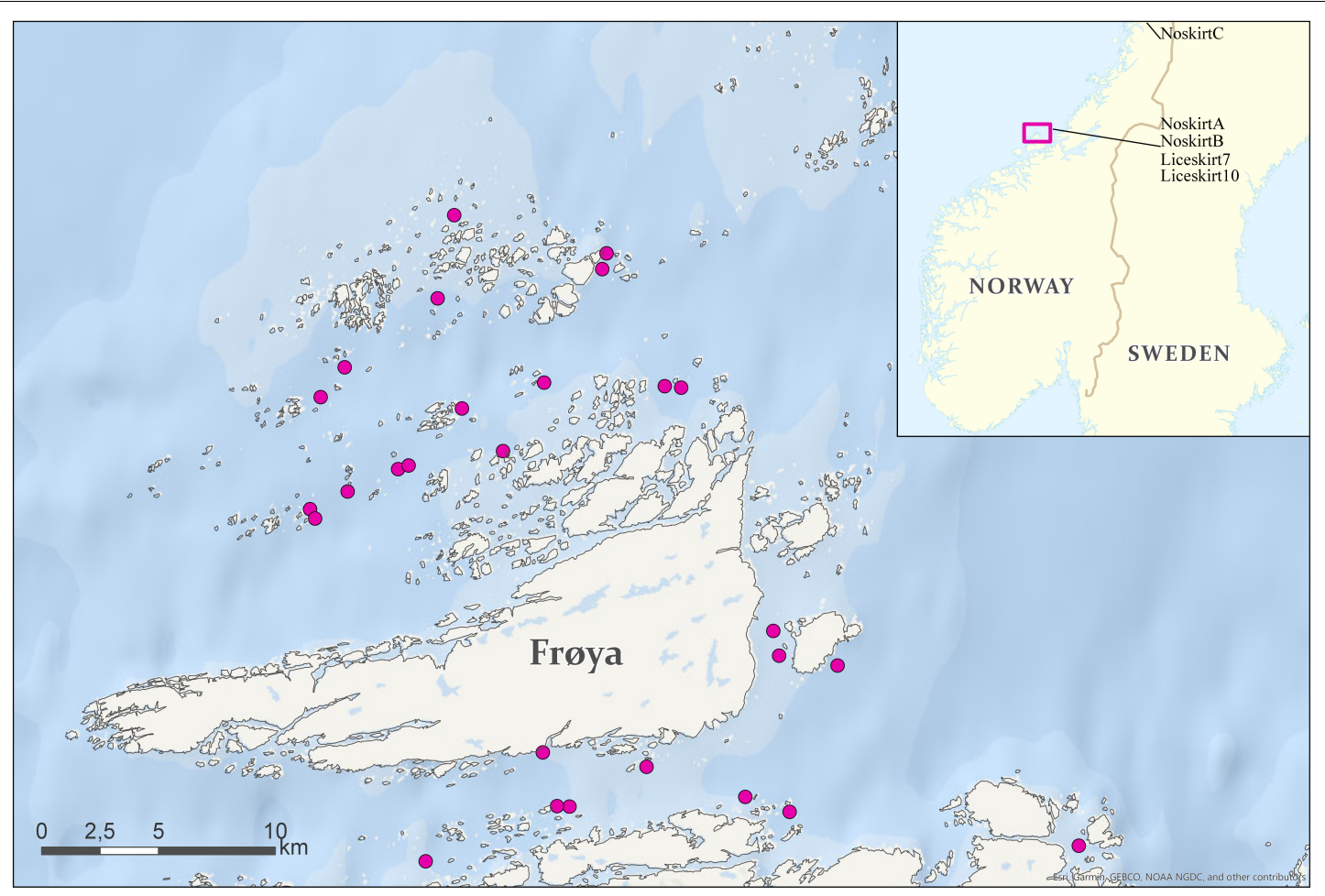

FIGURE 1 | Map over study area. Circles indicate salmon farms. Rough placement of sites is given in the small map. Map created by Tale Skrove. (C Kartverket @) Europa wms.

The objective of this study was to assess, by different methods, the extent to which planktonic sea lice utilize biofouling on submerged structures on salmon farms as a microhabitat and to determine if biofouling on net pens may create a retaining effect. These objectives were investigated through three experiments. Experiment A investigated the interaction between biofouling and planktonic sea lice, through analysis of the biofouling community on the cage-net and cleaner fish shelters. Experiment B investigated the interaction of biofouling and planktonic sea lice through possible resuspension after in situ net cleaning. Experiment $\mathrm{C}$ investigated if biofouling on the cage-nets could produce a retaining effect on the dispersal of planktonic sea lice.

\section{MATERIALS AND METHODS}

In Experiment $\mathrm{A}$, the sampling method captures sea lice that are directly associated with the biofouling and would not be dislodged by water currents, while Experiment B (Impact of net cleaning on sea lice abundance in water) captures a possible looser association between the sea lice and biofouling. Experiment $\mathrm{C}$ investigates the possible influence of biofouling on dispersal of planktonic sea lice through the cage-net.

Three of the five salmon farm sites studied were without lice skirts and are called NoskirtA, NoskirtB, and NoskirtC. Two sites had lice skirts that were placed around the upper part of the net pen. These sites are called Liceskirt7 (7-m deep lice skirts) and Liceskirt10 (10-m deep lice skirts). All the sites were located in Frøya municipality (634-51 N 8 $28-32$ E) in Central-Norway, except for NoskirtC (Kvarøy Fiskeoppdrett AS, Nordland) which was located in northern Norway $\left(66^{\circ} 25 \mathrm{~N}\right.$, $13^{\circ} 00$ E, Figure 1).

\section{Experiment A: Biofouling as a Sea Louse Habitat}

The first interaction between biofouling and planktonic sea lice studied was the possibility of biofouling harboring planktonic stages of sea lice (L. salmonis and C. elongatus). This interaction was studied through a case study assessing the sea lice content in the biofouling on structures at the NoskirtC site. NoskirtC is located in the municipality Lurøy in northern Norway, and consisted of 16 net pens ( $90 \mathrm{~m}$ circumference, $29 \mathrm{~m}$ diameter, $26 \mathrm{~mm}$ net size ${ }^{1}$ ).

A total of 12 impregnated net panels $(50 \mathrm{~cm} \times 50 \mathrm{~cm}$, $26 \mathrm{~mm}$ net size) were attached to the outside of the net pen using cable ties. Four net panels were placed at each of three depths $(1.5,5$, and $8 \mathrm{~m})$ evenly spread around the net pen. Both net panels and the net were coated with non-biocidal coating (Netpolish NP45, NetKem, Norway). The net panels were deployed at sea in May (week 18) and sampled by divers in October (week 40), which is the heart of the biofouling season.

\footnotetext{
${ }^{1}$ Net opening x 2 .
} 
During the time in sea, the net panels were subjected to the same regular in situ net cleaning (approximately every 10 days with high pressure, Guenther et al., 2010) as the net pens. The net panels were collected before biofouling removal of that net pen by in situ net cleaning later that day. The net panels were removed from the cage-net by divers and transferred carefully into zip-lock bags $(120-\mu \mathrm{m}$ mesh size) before transport to the surface. Each panel was stored in 96\% ethanol, together with the content of the zip-lock bags. In addition, parts of the 5$\mathrm{m}$ long cleaner fish shelter were collected. The cleaner fish shelter consisted of a series of plastic strands (approximately $0.5 \mathrm{~m} \times 0.15 \mathrm{~m}$, length $\times$ width) attached to a central rope (of a similar design of the single strand cleaner fish shelters produced by OK Marine, installed at 2-7 $\mathrm{m}$ depth). Ten strands from the top and 10 from the bottom of the shelter were collected in a similar manner as the net panels and fixed in $96 \%$ ethanol, in separate containers. Samples were stored at room temperature until analysis.

Samples were rinsed with freshwater on a filter $(120 \mu \mathrm{m}$, $49 \%$ light opening) prior to handling in order to wash off the ethanol. Samples were thereafter placed in a glass Petri dish (15 cm diameter) filled with water and analyzed using dissecting microscopes. All samples were analyzed in its entirety by meticulously examining the net panels square by square. A tweezer was used to part the epifauna for panels which contained high amounts of larger biofouling organisms (i.e., Mytilus edulis Linnaeus, 1758, and Bryozoa sp.), and in instances where these organisms could not be separated sufficiently, a tweezer was used to gradually pick the biofouling piece by piece until the net panels became visible. The remains in the Petri dish were carefully examined prior to analyzing subsequent panels. Thereafter, the remains contained in the sieve used to rinse the panels were transferred to the Petri dish and examined. Finally, the associated organisms from each panel were examined microscopically in its entirety. The cleaner fish shelter samples had less biofouling in general, which made them easy to examine microscopically, and was inspected in the same manner as the net panels.

\section{Experiment B: Impact of Net Cleaning on Sea Lice Abundance in Water}

Plankton sampling (vertical plankton tows) was used as a second method to study whether biofouling on the cage-net could harbor planktonic sea lice or not. In situ net cleaning was done with high pressure (Guenther et al., 2010).

Plankton samples from the sites NoskirtC and Liceskirt10 were analyzed to assess if sea lice would resuspend to the water during in situ net cleaning, and therefore potentially increase infestation pressure. The site Liceskirt10, located on the eastern side of the island Frøya, had five net pens (135-m circumference, 43-m diameter, $45 \mathrm{~mm}$ net size, see Experiment A for description of NoskirtC). Plankton samples from the NoskirtC site were taken downstream, outside the net pen before and during in situ net cleaning. The plankton samples were taken after sampling for Experiment A. Vertical plankton samples $(10-0 \mathrm{~m})$ were taken with a WP2 plankton net (150$\mu \mathrm{m}$ mesh size, 50-cm mouth opening, $2 \mathrm{~m}$ length), giving a sample volume of $1.96 \mathrm{~m}^{3}$ per tow (20 plankton tows before and during net cleaning, Table 1). The content of each tow was collected on a filter $(120 \mu \mathrm{m}, 49 \%$ open area), and transferred to separate sample bottles by flushing with ethanol (96\%) and thereafter stored at $10^{\circ} \mathrm{C}$ until they were analyzed. The stored samples were washed with filtered seawater on a filter $(120 \mu \mathrm{m}$, $49 \%$ open area) to remove the ethanol prior to laboratory analysis. Samples were then analyzed in full under a dissecting

TABLE 1 | Number of sampled net pens (replicates) for each site each sampling time or in each biofouling (BF) category (High BF: > 30\% coverage, Low BF: $\leq 30 \%$ coverage, High BF': lice skirt).

\begin{tabular}{|c|c|c|c|c|}
\hline Site & $\begin{array}{l}\text { Biofouling Score } \\
\text { or Sample Time }\end{array}$ & $\begin{array}{l}\text { Inside or Outside } \\
\text { Cage-Net }\end{array}$ & $\begin{array}{l}\text { Replicates (Number of Samples } \\
\text { Taken for Each Replicate) }\end{array}$ & $\begin{array}{c}\text { Replicates With } \\
\text { Planktonic Sea Lice }\end{array}$ \\
\hline NoskirtC & Before & Outside & $1(18)$ & $5^{b}$ \\
\hline NoskirtC & During & Outside & $1(20)$ & $9^{b}$ \\
\hline Liceskirt7 & High BF' & Inside & $24(2)$ & 16 \\
\hline Liceskirt7 & High $\mathrm{BF}^{\mathrm{L}}$ & Outside & $24(2)$ & 12 \\
\hline NoskirtA & High BF & Inside & $13(2)$ & 7 \\
\hline NoskirtA & High BF & Outside & $13(2)$ & 8 \\
\hline NoskirtA & Low BF & Inside & $9(2)$ & 6 \\
\hline NoskirtA & Low BF & Outside & $9(2)$ & 5 \\
\hline NoskirtB & High BF & Inside & $3\left(2^{a}\right)$ & 2 \\
\hline NoskirtB & High BF & Outside & $3\left(2^{a}\right)$ & 2 \\
\hline NoskirtB & Low BF & Inside & $20\left(2^{a}\right)$ & 7 \\
\hline NoskirtB & Low BF & Outside & $20\left(2^{a}\right)$ & 5 \\
\hline Liceskirt10 & Before & Inside & $11(2)$ & 8 \\
\hline Liceskirt10 & Before & Outside & $11(2)$ & 1 \\
\hline Liceskirt10 & After & Inside & $14(2)$ & 10 \\
\hline Liceskirt10 & After & Outside & $14(2)$ & 2 \\
\hline
\end{tabular}

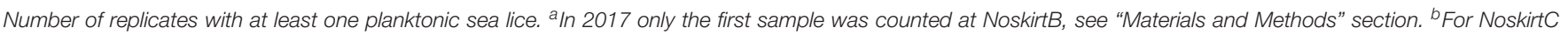
replicates with planktonic sea lice, shows samples with planktonic sea lice. 
microscope, and the stage of each planktonic sea louse was identified (nauplius I, nauplius II, or copepodite). Two of the samples from before in situ net cleaning were not analyzed due to time constraints.

Plankton samples at the Liceskirt10 site were taken prior to in situ net cleaning ( $n=11$ net pens), directly after in situ net cleaning ( $n=7$ net pens), and 1 day after in situ net cleaning ( $n=7$ net pens). At Liceskirt10 vertical plankton samples $(7-0 \mathrm{~m})$ were taken downstream both inside and outside the net pen with a WP2 plankton net (200- $\mu \mathrm{m}$ mesh size, $50-\mathrm{cm}$ mouth opening, $2 \mathrm{~m}$ length). The choice of a $200-\mu \mathrm{m}$ plankton tow was based on suggestions by an earlier study in order to reduce clogging of the plankton net (Schram, 2004). The later studies all utilized plankton tows with a mesh size of $150 \mu \mathrm{m}$, as clogging was not a problem, and $150 \mu \mathrm{m}$ is smaller than the width of all planktonic stages of sea lice (Schram, 2004).

The plankton net was equipped with a digital flow meter with back-run stop (KC Silkeborg, Denmark), placed inside the mouth of the plankton net (centered, $10 \mathrm{~cm}$ inside) to detect water flow through the net and ensure that potential clogging of the net could be adjusted for in calculations of sample volume. The sample volume was calculated according to the product specifications. Two plankton tows $(7-0 \mathrm{~m})$ were taken for each plankton sample. Two plankton samples were taken on the outside and on the inside at each sampled net pen each sampling time. Each plankton sample were treated as technical replicates, the results were pooled during calculations to give a replicate from the inside and one replicate from the outside of each net pen.

The content of each plankton tow was filtered on a coarse filter $(1,300 \mu \mathrm{m})$ in order to remove large debris. The filtered sample were then stirred by pouring them back and forth into two beakers before a sub-sample consisting of half the volume was transferred to bottles and fixated in buffered formaldehyde (formaldehyde $4 \%$ buffered with sodium tetraborate, $\mathrm{Na} 2[\mathrm{~B} 4 \mathrm{O} 5(\mathrm{OH}) 4] \cdot 8 \mathrm{H} 2 \mathrm{O}, 20 \mathrm{~g} \mathrm{~L}^{-1}$ formaldehyde). Samples were stored at $10^{\circ} \mathrm{C}$ until analysis.

In the laboratory the samples were sieved through a $500-\mu \mathrm{m}$ filter in order to remove coarser material but let the planktonic sea lice through (width $<300 \mu \mathrm{m}$, Schram, 2004). This method was based on what had been done in a study by Costelloe et al. (1996). The filtering step was eliminated during the subsequent studies, due to the possibility of planktonic sea lice also being filtered out (length can be $>500 \mu \mathrm{m}$ ). The sample was then collected on a $70 \mu \mathrm{m}$ filter and washed in filtered seawater to remove formaldehyde before analysis. The later experiments collected samples on 120 and $140-\mu \mathrm{m}$ filters to reduce clogging at this stage. Samples were then analyzed under a dissecting microscope. Planktonic sea lice larvae were identified as either nauplii or copepodites, but the species were not identified. However, they were likely L. salmonis or C. elongatus as these were the main species present on the salmon at the sites (see Supplementary Material).

No significant difference was found between the average density (see section "Statistical Methods") in replicates from after and 1 day after net cleaning, and results of the two sample times are presented together.

\section{Experiment C: Impact of Retention by Lice Skirts or Biofouling on Lice Concentration}

The last interaction between planktonic sea lice and biofouling investigated was the possible influence of biofouling on dispersal of planktonic sea lice out through the cage-net. This possible retention effect of the biofouling was investigated by comparing differences in planktonic sea lice concentrations inside and outside of the net pens related to the biofouling coverage on the cage-net. Because the cage-nets at the experiment sites (NoskirtA and NoskirtB) were changed when biofouling got too high, finding a fully biofouling-covered cage-net was not expected. Plankton samples were therefore also taken inside and outside of net pens with lice skirts (Liceskirt7). The lice skirts hinder the movement of planktonic sea lice through the cage-net and were used as an approximation of full biofouling coverage. The Liceskirt7 site used in situ net cleaning.

NoskirtA, NoskirtB, and Liceskirt7 had 9, 7, and 15 net pens, respectively (all $157 \mathrm{~m}$ circumference, $50 \mathrm{~m}$ diameter). Net sizes were 31, 35, and $35 \mathrm{~mm}$ for NoskirtA, NoskirtB, and Liceskirt7, respectively. Plankton tows were taken at three net pens $(n=3)$ at each site once in May, June, July, and September in 2017, and May, June, July, and August in 2018. All three sites stocked salmon from February to March 2017. Plankton tows were taken as described for the Liceskirt10 site, with the following exceptions: the coarser filter was 1,000 $\mu \mathrm{m}$, and the entire sample was filtered on a $140-\mu \mathrm{m}$ filter and the sample remaining on the filter were stored in $96 \%$ ethanol at $10^{\circ} \mathrm{C}$ until analysis. In the laboratory the sample was again collected on a $140-\mu \mathrm{m}$ filter to remove the ethanol, and then investigated under a stereomicroscope (at $0.78-16.0 \times$ ).

Samples containing large amounts of plankton organisms were divided into two sub-samples after mixing the sample volume by pouring it back and forth three times. One half was analyzed and the other stored for possible re-examination. This resulted in three types of replicate categories, Category 1 all samples from the pen were analyzed completely, Category 2 all samples from the pen were divided in two sub-samples and one half of each sample was analyzed and Category 3 (A) two samples were analyzed in their entirety and (B) the other two samples were divided with one half of each of the two analyzed. The coefficient of variation was calculated and compared for the three categories, to assess the impact of splitting samples. The same three sites from Experiment $C$ were sampled in the same manner as described above during the rest of the production cycle (between May 2017 and August 2018), and the data used for the calculation of the coefficient of variation was taken from this larger dataset. Coefficient of variation Category 1, $N=65$, 1.26; Category 2, $N=12,1.04$; and Category 3, $N=6$, (A) 1.12, (B) 1.15. The coefficients of variation for all three cases were high but comparable.

Based on the low lice levels on the site ( $\leq 0.3$ adult female lice per salmon during this period) and in the samples counted, the second sample from NoskirtB was not counted in 2017 due to time constraints. 
Biofouling abundance (\% coverage) in the vicinity of the plankton sample site was registered with a waterproof camera (KitVision Escape HD5W action camera) for each net pen. Films of the net were taken at a depth of $1.5 \mathrm{~m}$ at approximately $1 \mathrm{~m}$ distance to the net. Still images were captured from the film, and for each image $(n=3)$, biofouling coverage (\%) was quantified by determining the presence or absence of biofouling at 60 random spots selected by overlaying the image with a grid. If a spot landed on a mesh opening, the mesh strand to the immediate left was scored instead. For six of the sampled net pens (NoskirtA and NoskirtB, August 2018), the films were lost before multiple pictures could be taken and biofouling was analyzed on one picture only. In order to assess the effect of biofouling relative to its abundance, net pen biofouling was characterized either as low $(\leq 30 \%$ coverage) or high (>30\% coverage). This threshold was chosen in order to give enough observations in the high biofouling category. The same biofouling assessment was done for the Liceskirt7 site, however, as this site was used as an approximation of full biofouling coverage, the biofouling coverage is only given as a reference.

A CTD (conductivity, temperature, density: SAIV STD/CTD, model SD204) was used to record hydrography profiles (0-25 m, conductivity, temperature, pressure) at one of the outer floating buoys of the salmon farm sites (17-53 $\mathrm{m}$ from the closest net pen) on sample days from July 2017 onward. The CTD was lowered three times. Measurements were inspected visually, and obvious measurement errors were excluded (e.g., when one of the three profiles reported lower salinities in the surface water than the others). Because density is influenced by both temperature and salinity (Helber et al., 2012), we choose to show the density profiles in this paper.

\section{Comparing the Three Experiments}

Although direct comparison across studies with different methodology is questionable, the present study compares samples taken inside the net pen with samples taken with the same gear and method outside the same net pen. Because the bias from the sampling method should be the same for the two samples, comparing the difference between the inside samples and the outside samples across methods should be less affected by the different gears than comparing samples directly. It is the difference between the inside and outside samples which is compared across the different methods in this study.

\section{Statistical Methods}

The data were tested for normality using a Shapiro-Wilks test, and for homogeneity of variance by a Levene's test. The data were in almost all cases not normally distributed. Transforming the data did not make them normally distributed, and nonparametric tests were chosen to analyze the data. For the same reason, descriptive statistics are given by median \pm median absolute deviation (MAD) rather than by mean \pm standard deviation (SD), unless specified otherwise. The significance level was set at 0.05 unless specified otherwise. A KruskalWallis test, denoted as $\mathrm{H}$ (degrees of freedom), was used to compare group medians, with multiple comparisons done using the Mann-Whitney-Wilcoxon test with Bonferroni adjustment of the $p$-value. The distribution of planktonic sea lice is patchy (Skarohamar et al., 2019). This paper defines the terms "proportion-non-zero" as the percent of replicates containing sea lice larvae, and "average density" as the mean number of sea lice larvae $\mathrm{m}^{-3}$ seawater in the non-zero-replicates. In the calculation of correlation (Spearman's rho) between planktonic sea lice and abundance of biofouling on the cage-net, it was important to have all the samples represented by one variable and therefore mean abundance (ind. $\mathrm{m}^{-3}$ seawater all replicates) was utilized. A contingency table was used to find odds ratios (OR), 95\% confidence intervals (CI) by Fisher's exact test for count data, and the significance was found by Pearson's chi square test, denoted as $\chi^{2}$ (degrees of freedom, Warnes et al., 2018). Bias-correlated and accelerated (BCa) bootstrap (iterations $=2000)$ 95\% CIs were calculated for both percentnon-zero and density-non-zero (Reiczigel et al., 2019; Salvatore, 2019). Mean density-non-zero between groups were compared by a bootstrap $t$-test (iterations $=1000$, Rozsa et al., 2000). R version 3.6 (R Core Team, 2019) was used for all data processing and calculations.

\section{RESULTS}

\section{Biofouling as a Sea Louse Habitat}

Only one single sea louse nauplius was found among all net biofouling samples analyzed from the NoskirtC site (found on one of the net panel from $5 \mathrm{~m}$ depth). Moreover, no sea louse was detected among the biofouling on the cleaner fish shelter. With only one louse found, the effect of depth could not be investigated. Lice counts for all net pens at the site at the week of sampling averaged 0.12 adult female lice per salmon, and the sampled net pen had been between 0.09 and 0.15 adult female lice per salmon and between 1.45 and 1.95 Caligus elongatus per salmon the three last weeks (data from Kvarøy and database, BarentsWatch, 2020, June 22)2.

\section{Impact of Net Cleaning on Sea Lice Abundance in Water}

Net cleaning had no significant effect on average density of planktonic sea lice, outside the net pen, at the site NoskirtC [before: $0.92 \pm 0.43$ (SD) lice $\mathrm{m}^{-3}$, during: $0.85 \pm 0.36$ lice $\mathrm{m}^{-3}$; bootstrap two-sample $t$-test $=0.82, p=0.45$, Figure $2 \mathrm{E}]$. The proportion-non-zero increased during net cleaning $(0.45, n=20$, BCa 95\% CI $=0.20-0.65)$, but was not significantly different from before net cleaning $(0.28, n=18, \mathrm{BCa} 95 \% \mathrm{CI}=0.6-0.44$, Figure 3D). Only nauplii were found in the plankton samples from this site (Table 2).

Net cleaning had no significant effect on the average density of planktonic sea lice, inside the net pen at the site Liceskirt10 (before: 4.78 ind $\mathrm{m}^{-3}$ seawater, BCa 95\% CI $=2.08-12.40$, after: 1.68 ind. $\mathrm{m}^{-3}$ seawater, $\mathrm{BCa} 95 \% \mathrm{CI}=1.18-2.57$; bootstrap two-sample $t$-test $=1.27, p=0.38$, Figure 2D). Samples from the outside showed even lower differences

\footnotetext{
${ }^{2}$ https://www.barentswatch.no/en/download/fishhealth/lice
} 

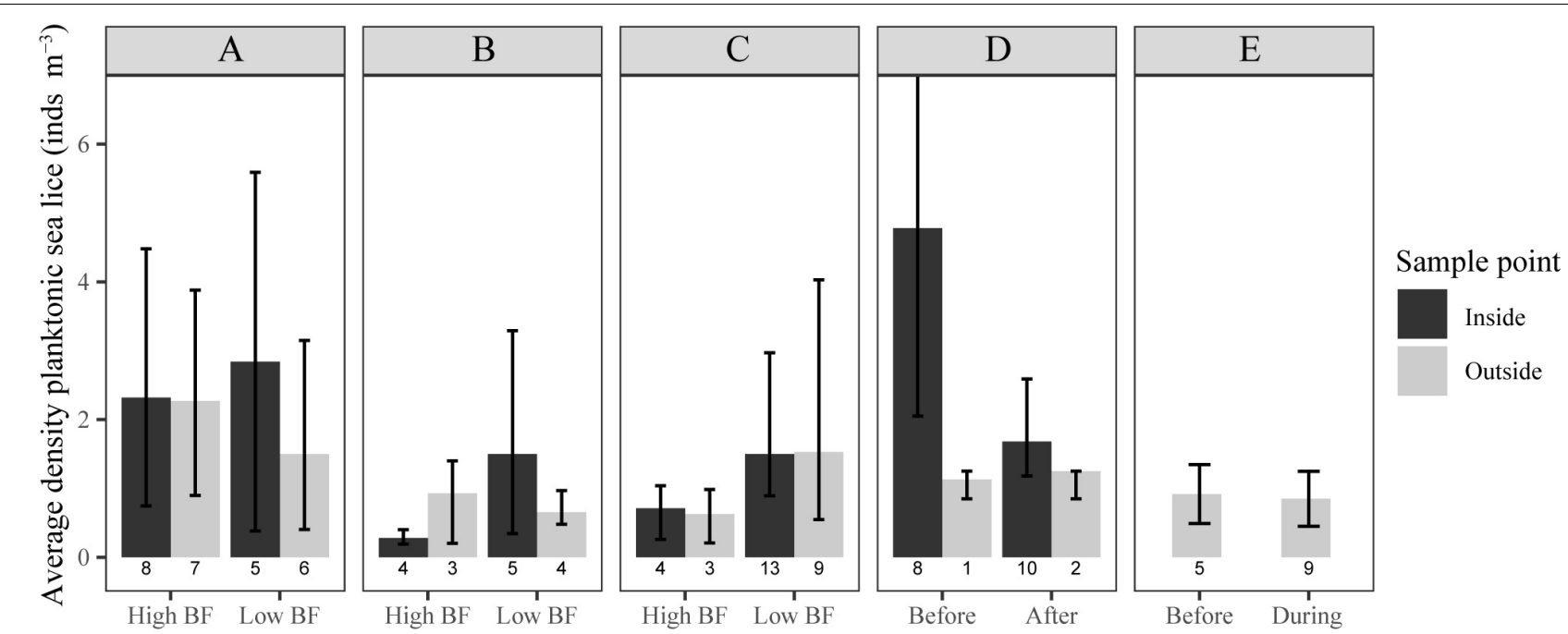

FIGURE 2 | Average density of planktonic sea lice (individuals $\mathrm{m}^{-3}$, is based on only those replicates containing at least one sea louse) for samples taken from the inside (black bar) and outside (gray bar). Divided for experiment and site [NoskirtA (A), NoskirtB (B), Liceskirt7 (C), Liceskirt10 (D), NoskirtC (E)], and biofouling category [Hight biofouling (BF): biofouling $\geq 30 \%$, Low BF: biofouling < 30\%, Lice skirt High BF: site has lice skirt and it is assumed to act as High BF] Total number of replicate net pens in each category is shown under the bars. Error bars show Bias-corrected and accelerated bootstrap (2000) 95\% confidence intervals for (A-D), and standard deviation for (E).

TABLE 2 | Total number of nauplii and copepodites of sea lice found in plankton samples (vertical plankton tows) from the five sites.

\begin{tabular}{|c|c|c|c|c|c|}
\hline Licestage & NoskirtC & Liceskirt10 & NoskirtA & NoskirtB & Liceskirt7 \\
\hline Nauplii & 15 & 77 & 239 & 59 & 173 \\
\hline Copepodites & 0 & 1 & 4 & 1 & 1 \\
\hline (In which samples) & & $\begin{array}{l}\text { (Inside net pen, before } \\
\text { in situ net cleaning) }\end{array}$ & $\begin{array}{l}\text { (Outside, at both high and } \\
\text { low biofouling) }\end{array}$ & $\begin{array}{l}\text { (Inside, low } \\
\text { biofouling) }\end{array}$ & (Inside) \\
\hline
\end{tabular}

(Figure 2D). For Liceskirt10, the proportion-non-zero data did not allow the calculation of individual odds ratios for each sample time due to a violation of the minimum expected frequency assumption. Differences between sample times were, however, rather small compared to differences between sample points (inside $v s$. outside, Figure $3 \mathrm{C}$ ). When all inside samples were compared with all outside samples at Liceskirt10, there was a significantly higher likelihood of finding planktonic sea lice in samples from the inside than in samples from the outside (Table 3). For plankton samples from this site, only one copepodite was found (inside the net pen, before in situ net cleaning).

\section{Impact of Retention by Lice Skirt or Biofouling on Lice Abundance}

Density profiles of the seawater, for the sites showed no clear stratification of the water masses above $20 \mathrm{~m}$ for all sampling days (Figure 4), there was found no clear thermoclines or haloclines either (data not shown).

Biofouling coverage at the time of sampling varied between 0 and $99 \%$ and differed significantly only between sites NoskirtA and Liceskirt7 (NoskirtA: $47 \pm 42 \%$, the median of all sampled net pens \pm median absolute deviation, MAD, NoskirtB: $12 \% \pm 15 \%$, Liceskirt7: $3 \pm 5 \%, H(2)=10.23, p=0.006)$.
Planktonic sea lice were found in $44 \%$ of the samples, with $16 \%$ of all samples containing one planktonic sea louse. The mean abundance of adult female lice on salmon, for all months sampled, were $0.08 \pm 0.22$ (mean $\pm \mathrm{SD}$ ) and $0.14 \pm 0.41$ for NoskirtA and NoskirtB, respectively. The median \pm MAD for the same localities were both $0.00 \pm 0.00$. No significant correlation was found between biofouling abundance and mean abundance of planktonic sea lice (Spearman's rho $=0.10, p=0.23$, Figure 5).

The odds ratio (OR) for the proportion-non-zero of samples taken on the inside and samples taken on the outside were

TABLE 3 | Odds ratios (OR) for proportion-non-zero of planktonic sea lice found in the inside samples and outside samples.

\begin{tabular}{lccccc}
\hline Site & $\boldsymbol{n}$ & OR & Lower 95\% Cl & Upper 95\% Cl & $\boldsymbol{p}$ \\
\hline NoskirtAB & & & & & \\
Low BF & 58 & 1.53 & 0.47 & 5.10 & 0.42 \\
High BF & 32 & 0.78 & 0.15 & 3.93 & 0.72 \\
All & 90 & 1.19 & 0.48 & 2.97 & 0.67 \\
Liceskirt7 & 48 & 2.02 & 0.54 & 8.08 & 0.23 \\
Liceskirt10 & 25 & 17.4 & 3.6 & 120.4 & $<0.001$
\end{tabular}

Upper and lower 95\% confidence interval (Cl) found by Fisher's exact test for count data. P-value was found by Pearson's chi square test. 

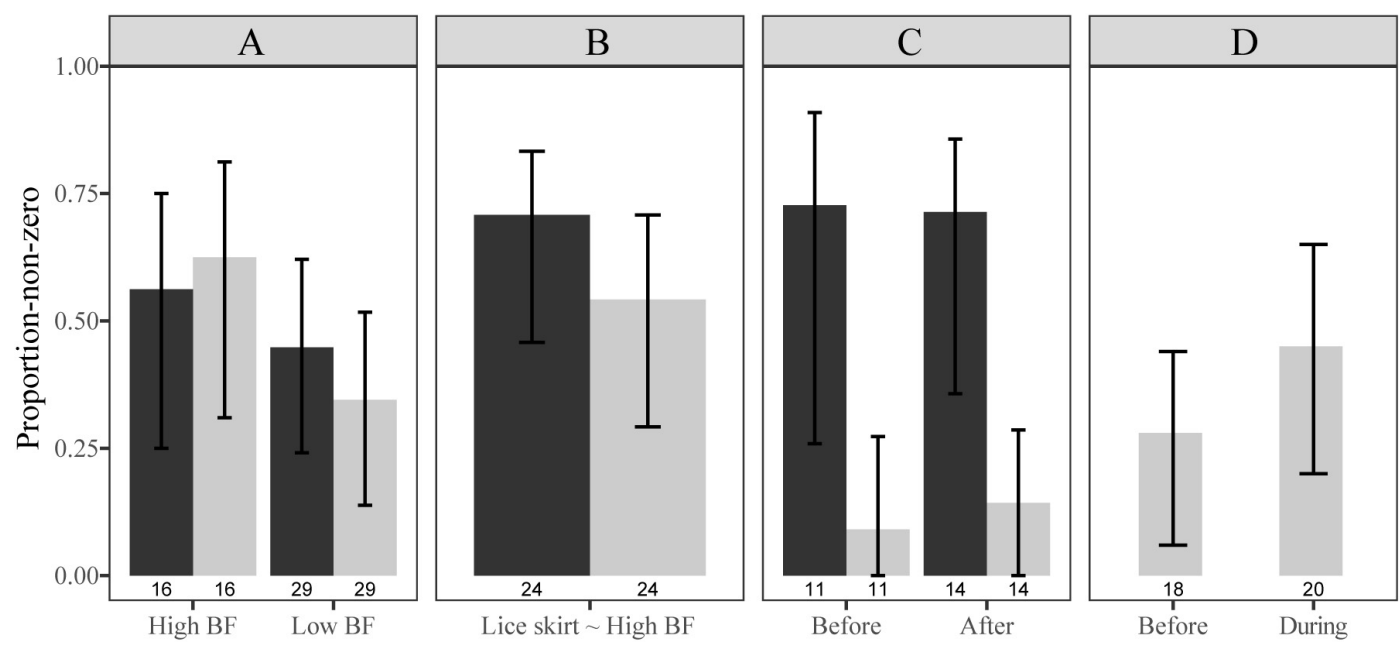

Sample point

Inside

Outside

FIGURE 3 | Proportion-non-zero (proportion of replicates with at least one sea louse) for samples taken from the inside (black bar) and outside (gray bar). Divided for experiment and site [(column panels, NoskirtA and NoskirtB (A), Liceskirt7 (B), Liceskirt10 (C), NoskirtC (D)], and biofouling category [row panels, Hight biofouling (BF): biofouling $\geq 30 \%$, Low BF: biofouling $<30 \%$, Lice skirt High BF: site has lice skirt and it is assumed to act as High BF]. Total number of replicate net pens in each category is shown by $n=x$ under the bars. Error bars show Bias-corrected and accelerated bootstrap (2000) 95\% confidence intervals.

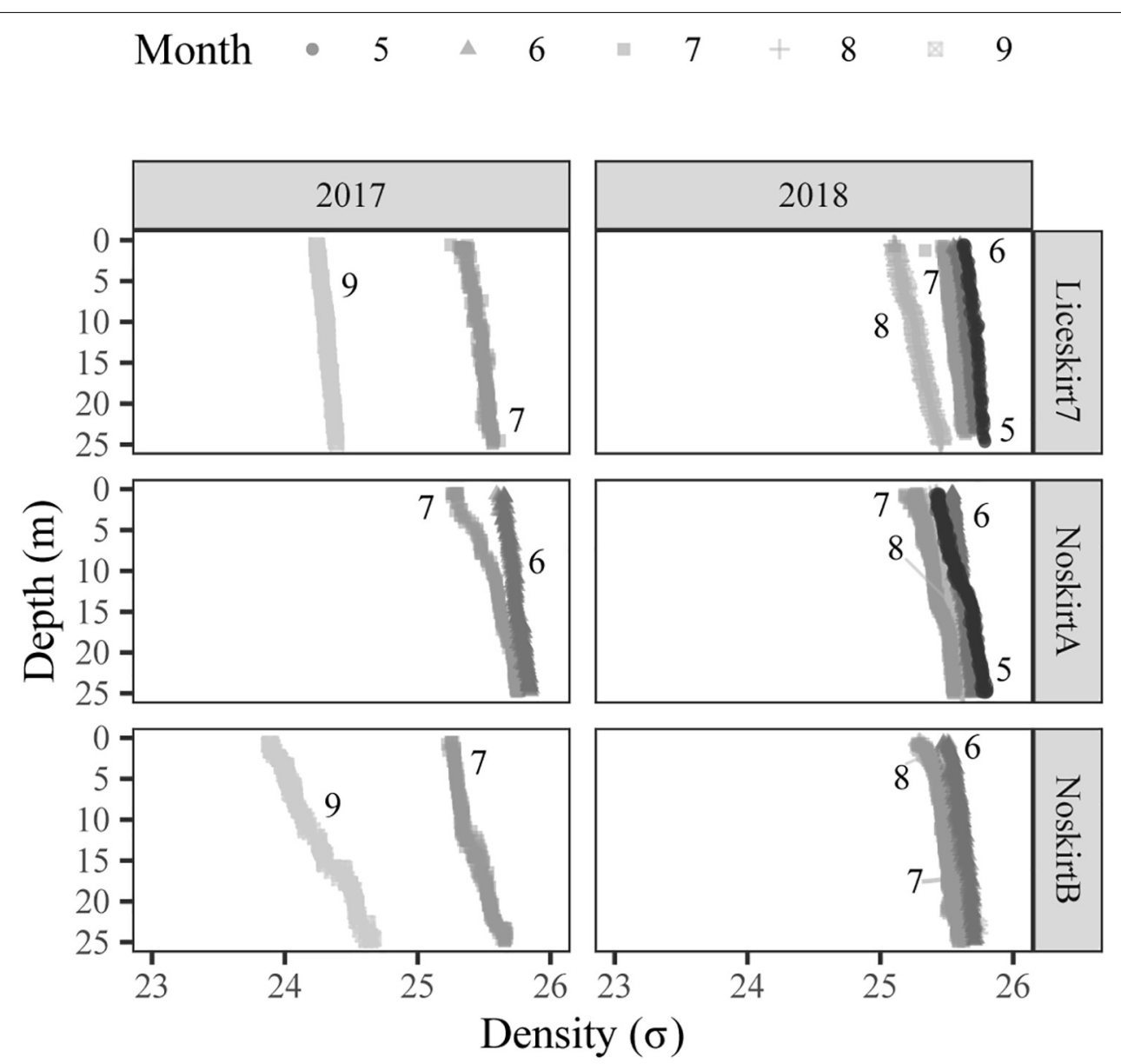

FIGURE 4 | Density $(\sigma)$ profiles of the seawater with depth $(m)$ at the time of sampling for each sample site. Shade and symbol illustrate which month the profile was taken from, in addition the number of the month is given next to the profile. 


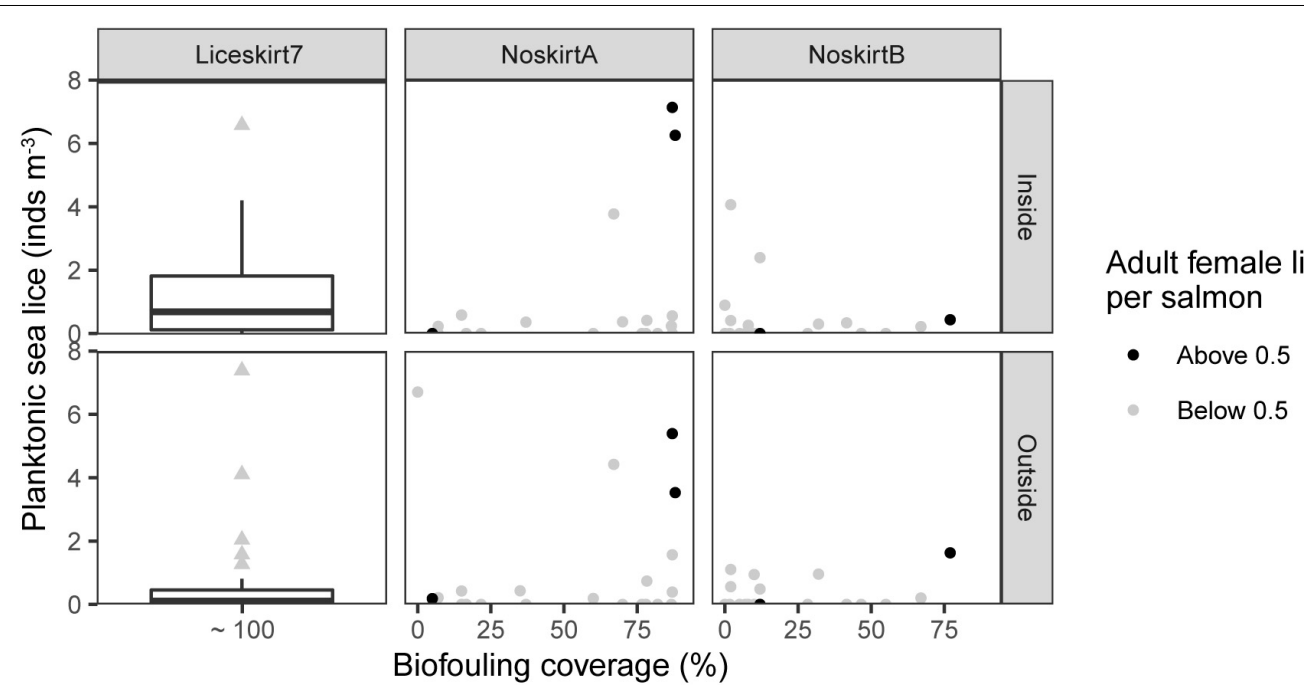

FIGURE 5 | Mean abundance of planktonic sea lice per $\mathrm{m}^{3}$ seawater as a boxplot (Liceskirt7) or as a function of the biofouling on the cage-net (NoskirtA and NoskirtB). Results are shown for the three net pens on each of the three sites, taken inside and outside of the pen. Fill color indicates if the number of adult female lice in the sampled net pen were above or below 0.5 the same week, or the prior week. Liceskirt7: individual points categorized as outliers in the boxplot (more than 1.5 times the interquartile range from the box).

not significant for both the high and low biofouling categories (Table 3 and Figure 3A). There was, moreover, no difference found for the average density on either the inside or outside of net pens between these two categories (bootstrap $t$-test $p>0.05$, Figure 2). There were no significant differences between the inside and outside when comparing average density on the NoskirtA and NoskirtB sites (bootstrap twosample $t$-test $=0.927, p=0.37$ ). No significant differences were found for the proportion-non-zero (Table 3 and Figure 3B) or average density (bootstrap two-sample $t$-test $=0.26$, $p=0.81$ ) of planktonic sea lice between samples found on the inside and outside of the Liceskirt7 site. Nauplii represented the majority of the life stages found for all sites (Table 2).

\section{DISCUSSION}

\section{Biofouling as a Sea Louse Habitat}

No evidence was found in this study for any association between the biofouling community on salmon cage-nets and planktonic sea lice. This lack of association cannot be attributed to a lack of sea lice in the environment as they were present on the salmon at the NoskirtC site and in the plankton tow samples. Our observations revealed only one single nauplius of sea lice in the biofouling samples. Other individuals of copepod species, mainly of the orders Calanoida and Harpacticoida, were observed in large abundance among the biofouling on the cage-net, the cleaner fish shelter and the associated fauna. The harpacticoid copepods, which are mainly associated to benthic substrates, were usually found deep in the biofouling, and were similar to the copepodite stages of sea lice both in terms of morphology and size. Hence, special attention was paid to the inspection of harpacticoid copepods during sampling to ensure that they were not mistaken for sea lice. Although there is always an inherent risk of plankton escaping the notice of the observer during microscopic analyses, the sampling method nonetheless had a high enough resolution to detect sea lice. Others have found copepods in association with biofouling communities (JelicMrcelic et al., 2006) and similar to other associated macroorganisms, these are most likely attracted to the cage-nets due to easily accessible food (Davenport et al., 2009). A similar attraction is unlikely for planktonic sea lice stages as they are non-feeding lecithotrophic species (Tucker et al., 2000). Despite the limited temporary resolution and challenging sampling methodology, our present finding makes us conclude that there is a lack of association between planktonic sea lice and the biofouling on the net.

\section{Impact of Net Cleaning on Sea Lice Abundance}

Net cleaning did not lead to an increase in proportion-nonzero replicates or average density of sea lice in the water column in NoskirtC or Liceskirt10, indicating that there was no resuspension of sea lice from the biofouling on the net, or that they were destroyed in the process. Net cleaning conducted with high-pressure washers removes all biofouling from the net, and often fracturing larger particles in that process (Carl et al., 2011). It is therefore unlikely that any sea lice potentially attached to the net or biofouling could have remained on the net just after cleaning. This provides further evidence that sea lice are not associated with the net biofouling community. If they were destroyed to such an extent that they unidentifiable under a microscope, they are unlikely to be able to infest a salmon afterward. Based on all these observations, we conclude 
that sea lice unlikely utilize biofouling on the salmon farm as a microhabitat, whether actively or passively.

\section{Impact of Retention by Lice Skirt or Biofouling on Lice Abundance}

This study did not reveal any evidence for a change in larval dispersal over the net between the cage-nets that had low and high biofouling (NoskirtA and NoskirtB). No significant difference was found between the inside samples and outside samples for the Liceskirt7 site. This contrasts with the findings from the Liceskirt10 site, where a higher proportion-non-zero replicates was found for the inside samples (Table 3). This difference is in accordance with earlier observations where some studies reports a higher concentrations of planktonic sea lice inside net pens compared to outside (Costelloe et al., 1996) and others report no difference (Nelson et al., 2018). A possible retaining effect by lice skirts or biofouling might be linked to the same factors that that make a lice skirt effective in shielding the salmon from copepodites.

The effectiveness of the lice skirts can be reduced by environmental conditions like the presence of a cline deeper in the water than the lower edge of the lice skirt, which have been shown for the presence of a halocline (Samsing et al., 2016; Oppedal et al., 2019). We investigated the water profile for haloclines, thermoclines, and pycnoclines (only the latter is shown in this paper, because the density of seawater is a function of salinity and temperature, Helber et al., 2012); however, we found no clines for the Liceskirt7 site. This lack of a cline might suggest that that the water could mix down below the depth of the lice skirt. If mixing did occur that could explain the lack of significant differences in both proportion-non-zero and average density of planktonic sea lice between the samples taken on the inside and outside of the Liceskirt7 site. Flow around a cage is affected by both flow conditions on the site and local topography in addition to the structures on the farm (Klebert et al., 2013; Frank et al., 2015). The different results between the two sites with lice skirts could therefore be due to the deeper lice skirts at Liceskirt10, but also because of differences in the environment they are situated in. The dispersal of planktonic stages of sea lice out of the cage are likely affected by such differences, and the low proportion-non-zero in the outside samples from Liceksirt10 might be a result of a retaining effect by the lice skirt, the sampling place not capturing the plankton stages dispersing out of the net pen or perhaps a combination of both. The higher proportionnon-zero on the inside could still be of concern if it allows the nauplii produced inside the net pen to remain inside the net pen or close to the site for the time it needs to develop into a copepodite. This could increase the internal infestation pressure in the net pen or on the site. The observed differences between the two sites emphasize the need for further studies to better understand the relationship between skirt depths, environmental conditions, and degree of protection offered by lice skirts.

The subsampling involving splitting of samples did not have any impact on sample quality. The high coefficients of variation indicated a high variability in the number of planktonic sea lice found in samples taken from the same net pen at small time intervals. Sampling one net pen usually took $50 \pm 12 \mathrm{~min}$, depending on the weather conditions and the experience of the persons doing the sampling. High variation in numbers of planktonic sea lice found in the plankton tows is consistent with the corresponding results in earlier reports (Byrne et al., 2018; Nelson et al., 2018). This study utilized the traditional light microscope, however, there are other methods that could have been utilized. Molecular methods have been used to detect salmon lice in plankton samples (McBeath et al., 2006), and realtime PCR can be used in combination with light microscope to identify the species after planktonic sea lice are found in a light microscope (á Norðði et al., 2015). Other methods such as fluorescence microscope (Thompson, 2020), digital droplet PCR (Alsvik, 2019) are being looked into for utilization in enumeration of planktonic sea lice.

\section{CONCLUSION}

Our study revealed that sea lice, and therefore salmon lice, did not use net biofouling as a microhabitat in their planktonic stages. The presence of biofouling did not appear to have any influence on the dispersion of planktonic sea lice. Lice skirts, in contrast, can have an impact on the dispersion and may create a retaining effect, depending on skirt depths and the environmental conditions. Further research is needed to fully understand the mechanisms for the exchange of planktonic sea lice between a salmon net pen with a lice skirt and the surrounding water, the infestation dynamics of salmon lice, and the efficiency of deploying skirts for combatting sea lice problems in salmon farms.

\section{DATA AVAILABILITY STATEMENT}

The datasets presented in this article are not readily available because the dataset contains production data, which is not public. Requests to access the datasets should be directed to lone.s.jevne@gmail.com.

\section{AUTHOR CONTRIBUTIONS}

LJ planned and carried out the fieldwork of Experiments B and $\mathrm{C}$, analyzed a large part of the plankton samples, and did all data treatment and the main part of writing the manuscript. $\mathrm{AH}$ and KS contributed to fieldwork, data analysis, and writing of Experiment A. MØ participated in the fieldwork, analysis of samples, and the writing process of Experiment $\mathrm{B} . \mathrm{AB}$ and NB contributed to planning, analysis of samples, and writing. $\mathrm{KR}$ and $\mathrm{YO}$ acquired funding and participated in the planning and writing process. All authors contributed to the article and approved the submitted version.

\section{FUNDING}

This study was part of the project, Taskforce Salmon lice at NTNU, funded by the salmon industry in Central-Norway and the Norwegian Seafood Research Fund (project number 901241), and the project, "New industry in the North", 
funded by the Barents2020-programme (phase 1), Innovation Norway (phase 2), and Kvarøy Fiskeoppdrett AS.

\section{ACKNOWLEDGMENTS}

We would like to thank Kvarøy Fiskeoppdrett AS, for initiating and facilitating the experiment in Northern-Norway, and Maria Leitet and Leonore Olsen, for their contributions to sampling, experiment planning, and funding acquisition. We would also like to thank Maria Guttu and Øystein

\section{REFERENCES}

á Norðði, G., Simonsen, K., Danielsen, E., Eliasen, K., Mols-Mortensen, A., Christiansen, D. H., et al. (2015). Abundance and distribution of planktonic Lepeophtheirus salmonis and Caligus elongatus in a fish farming region in the Faroe Islands. Aquac. Environ. Interact. 7, 15-27. doi: 10.3354/aei00134

Abolofia, J., Wilen, J. E., and Asche, F. (2017). The cost of lice: quantifying the impacts of parasitic sea lice on farmed salmon. Mar. Resour. Econ. 32, 329-349. doi: $10.1086 / 691981$

Alsvik, M. (2019). The Response of Salmon Lice Nauplii and Copepodids (Lepeophtheirus salmonis) to Artificial Light Stimuli. Master thesis, Norwegian University of Science and Technology, Trondheim.

Asplin, L., Johnsen, I. A., Sandvik, A. D., Albretsen, J., Sundfjord, V., Aure, J., et al. (2014). Dispersion of salmon lice in the hardangerfjord. Mar. Biol. Res. 10, 216-225. doi: 10.1080/17451000.2013.810755

Bannister, J., Sievers, M., Bush, F., and Bloecher, N. (2019). Biofouling in marine aquaculture: a review of recent research and developments. Biofouling 35, 1-18.

BarentsWatch (2020). Open Data Via Webpage BarentsWatch. In: Røeggen A (ed). Available online at: https://www.barentswatch.no/en/download/fishhealth/lice (accesses June 22, 2020).

Bi, C. W., Zhao, Y. P., Dong, G. H., Wu, Z. M., Zhang, Y., and Xu, T. J. (2018). Drag on and flow through the hydroid-fouled nets in currents. Ocean Eng. 161, 195-204. doi: 10.1016/j.oceaneng.2018.05.005

Boxaspen, K. (2006). A review of the biology and genetics of sea lice. ICES J. Mar. Sci. 63, 1304-1316. doi: 10.1016/j.icesjms.2006.04.017

Bricknell, I. R., Dalesman, S. J., O’Shea, B., Pert, C. C., and Luntz, A. J. (2006) Effect of environmental salinity on sea lice Lepeophtheirus salmonis settlement success. Dis. Aquat. Organ. 71, 201-212. doi: 10.3354/dao071201

Bron, J. E., Sommerville, C., Wootten, R., and Rae, G. H. (1993). Fallowing of marine Atlantic salmon, Salmo salar L, farms as a method for the control of sea lice, Lepeophtheirus salmonis (Krøyer, 1837). J. Fish Dis. 16, 487-493. doi: 10.1111/j.1365-2761.1993.tb00882.x

Byrne, A. A., Pearce, C. M., Cross, S. F., and Jones, S. R. M. (2018). Planktonic and parasitic stages of sea lice (Lepeophtheirus salmonis and Caligus clemensi) at a commercial Atlantic salmon (Salmo salar) farm in British Columbia, Canada. Aquaculture 486, 130-138. doi: 10.1016/j.aquaculture.2017.12.009

Carl, C., Guenther, J., and Sunde, L. M. (2011). Larval release and attachment modes of the hydroid Ectopleura larynx on aquaculture nets in Norway. Aquac. Res. 42, 1056-1060. doi: 10.1111/j.1365-2109.2010.02659.x

Costello, M. J. (2006). Ecology of sea lice parasitic on farmed and wild fish. Trends Parasitol. 22, 475-483. doi: 10.1016/j.pt.2006.08.006

Costelloe, M., Costelloe, J., and Roche, N. (1996). Planktonic dispersion of larval salmon-lice, Lepeophtheirus salmonis, associated with cultured salmon, Salmo salar, in western Ireland. J. Mar. Biol. Assoc.U. K. 76, 141-149. doi: 10.1017/ s0025315400029064

Crosbie, T., Wright, D. W., Oppedal, F., Dalvin, S., Myksvoll, M. S., and Demptster, T. (2020). Impact of thermoclines on the vertical distribution of salmon lice larvae. Aquac. Environ. Interact. 12, 1-10. doi: 10.3354/aei00344

Crosbie, T., Wright, D. W., Oppedal, F., Johnsen, I. A., Samsing, F., and Dempster, T. (2019). Effects of step salinity gradients on salmon lice larvae behaviour and dispersal. Aquac. Environ. Interact. 11, 181-190. doi: 10.3354/aei00303

Davenport, J., Black, K. D., Burnell, G., Cross, T., Black, K., Mulcah, M., et al. (2009). Aquaculture: the Ecological Issues. Hoboken, NJ: John Wiley \& Sons.
Dimmen, for contributions in the field, and Zsolt Volent and Kristbjörg Edda Jónsdóttir, for discussions on hydrodynamics around net pens.

\section{SUPPLEMENTARY MATERIAL}

The Supplementary Material for this article can be found online at: https://www.frontiersin.org/articles/10.3389/fmars. 2020.00727/full\#supplementary-material

Deady, S., Varian, S. J. A., and Fives, J. M. (1995). The use of cleaner-fish to control sea lice on two Irish salmon (Salmo salar) farms with particular reference to wrasse behaviour in salmon cages. Aquaculture 131, 73-90. doi: 10.1016/00448486(94)00331-h

Delauney, L., Compere, C., and Lehaitre, M. (2010). Biofouling protection for marine environmental sensors. Ocean Sci. 6, 503-511. doi: 10.5194/os-6-5032010

Eliasen, K., Danielsen, E., Johannesen, A., Joensen, L. L., and Patursson, E. J. (2018). The cleaning efficacy of lumpfish (Cyclopterus lumpus L.) in Faroese salmon (Salmo salar L.) farming pens in relation to lumpfish size and seasonality. Aquaculture 488, 61-65. doi: 10.1016/j.aquaculture.2018.01.026

Fitridge, I., Dempster, T., Guenther, J., and de Nys, R. (2012). The impact and control of biofouling in marine aquaculture: a review. Biofouling 28, 649-669. doi: 10.1080/08927014.2012.700478

Floerl, O., Sunde, L. M., and Bloecher, N. (2016). Potential environmental risks associated with biofouling management in salmon aquaculture. Aquac. Environ. Interact. 8, 407-417. doi: 10.3354/aei00187

Forskrift om lakselusbekjempelse (2020a). Forskrift om Lakselusbekjempelse. Forskrift om Bekjempelse av Lakselus i Akvakulturanlegg. nr 6 Måling av Sjøtemperatur og Telling av Lakselus [Regulations on Salmon Lice Control. Regulations on Combating Salmon Lice in Aquaculture Plants. No. 6 Measurement of Sea Temperature and Counting of Sea Lice]. In: Fiskeridepartementet N-o (ed). Oslo: Naerings- og fiskeri department. doi: 10.3354/aei00187

Forskrift om lakselusbekjempelse (2020b). Forskrift om Lakselusbekjempelse. Forskrift om Bekjempelse av Lakselus i Akvakulturanlegg. nr 8 Grenser for Lakselus og Tiltak [Regulations 518 on Salmon Lice Control. Regulations on Combating Salmon Lice in Aquaculture Plants. No. 8 Limits to Salmon Lice and Measures]. In: Fiskeridepartementet N-o (ed). Oslo: Naerings- og fiskeridepartementet.

Frank, K., Gansel, L. C., Lien, A. M., and Birkevold, J. (2015). Effects of a shielding skirt for prevention of sea lice on the flow past stocked salmon fish cages. J. Offshore Mech. Arct. Eng. Trans. ASME 137:260.

Gormican, S. J. (1989). Water Circulation, Dissolved Oxygen, and Ammonia Concentrations in Fish-Net Cages. Master's thesis, The University of British Columbia, Vancouver.

Guenther, J., Carl, C., and Sunde, L. M. (2009). The effects of colour and copper on the settlement of the hydroid Ectopleura larynx on aquaculture nets in Norway. Aquaculture 292, 252-255. doi: 10.1016/j.aquaculture.2009.04.018

Guenther, J., Misimi, E., and Sunde, L. M. (2010). The development of biofouling, particularly the hydroid Ectopleura larynx, on commercial salmon cage nets in Mid-Norway. Aquaculture 300, 120-127. doi: 10.1016/j.aquaculture.2010.01. 005

Helber, R. W., Kara, A. B., Richman, J. G., Carnes, M. R., Barron, C. N., Hurlburt, H. E., et al. (2012). Temperature versus salinity gradients below the ocean mixed layer. J. Geophys. Res. 117:5006. doi: 10.1029/2011jc007382

Heuch, P. A., Parsons, A., and Boxaspen, K. (1995). Diel vertical migration: a possible host-finding mechanism in salmon louse (Lepeophtheirus salmonis) copepodids? Can. J. Fish. Aquat. Sci. 52, 681-689. doi: 10.1139/f95-069

Hevrøy, E. M., Boxaspen, K., Oppedal, F., Taranger, G. L., and Holm, J. C. (2003). The effect of artificial light treatment and depth on the infestation of the sea louse Lepeophtheirus salmonis on Atlantic salmon (Salmo salar L.) culture. Aquaculture 220, 1-14. doi: 10.1016/s0044-8486(02)00189-8 
Imsland, A. K., Reynolds, P., Eliassen, G., Hangstad, T. A., Nytrø, A. V., Foss, A., et al. (2015). Assessment of suitable substrates for lumpfish in sea pens. Aquac. Intern. 23, 639-645. doi: 10.1007/s10499-014-9840-0

Iversen, A., Hermansen, Ø, Nystøyl, R., and Hess, E. J. (2017). Kostnadsutvikling $i$ Lakseoppdrett [Cost Development in Salmon Farming]. Tromsø, NO: Nofima.

Jelic-Mrcelic, G., Sliskovic, M., and Antolic, B. (2006). Biofouling communities on test panels coated with TBT and TBT-free copper based antifouling paints. Biofouling 22, 293-302. doi: 10.1080/08927010600912291

Johnson, S. C., and Albright, L. J. (1991). Development, growth, and survival of Lepeophtheirus salmonis (Copepoda: Caligidae) under laboratory conditions. J. Mar. Biol. Assoc. U. K. 71, 425-436. doi: 10.1017/s0025315400051687

Johnson, S. C., Treasurer, J. W., Bravo, S., Nagasawa, K., and Kabata, Z. (2004). A review of the impact of parasitic copepods on marine aquaculture. Zool. Stud. 43, 229-243.

Klebert, P., Lader, P., Gansel, L., and Oppedal, F. (2013). Hydrodynamic interactions on net panel and aquaculture fish cages: a review. Ocean Eng. 58, 260-274. doi: 10.1016/j.oceaneng.2012.11.006

Kvenseth, P. G. (1996). "Large-scale use of wrasse to control sea lice and net fouling in salmon farms in Norway," in Proceedings of the Wrasse Biology and Aquaculture Applications, eds M. D. J. Sayer, J. W. Treasurer, and M. J. Costello (Oban: Blackwell), 196-203.

Liu, Y., and Bjelland, H. V. (2014). Estimating costs of sea lice control strategy in Norway. Prevent. Vet. Med. 117, 469-477. doi: 10.1016/j.prevetmed.2014.08. 018

McBeath, A. J., Penston, M. J., Snow, M., Cook, P. F., Bricknell, I. R., Cunningham, C. O., et al. (2006). Development and application of real-time PCR for specific detection of Lepeophtheirus salmonis and Caligus elongatus larvae in Scottish plankton samples. Dis. Aquat. Organ. 73, 141-150. doi: 10.3354/dao073141

Nelson, E. J., Robinson, S. M. C., Feindel, N., Sterling, A., Byrne, A., and Pee Ang, K. (2018). Horizontal and vertical distribution of sea lice larvae (Lepeophtheirus salmonis) in and around salmon farms in the Bay of Fundy, Canada. J. Fish Dis. 41, 885-899. doi: 10.1111/jfd.12692

Nordi, G. A., Simonsen, K., and Patursson, O. (2016). A method of estimating in situ salmon louse nauplii production at fish farms. Aquac. Environ. Interact. 8, 397-405. doi: 10.3354/aei00185

Oppedal, F., Bui, S., Stien, L. H., Overton, K., and Dempster, T. (2019). Snorkel technology to reduce sea lice infestations: efficacy depends on salinity at the farm site, but snorkels have minimal effects on salmon production and welfare. Aquac. Environ. Interact. 11, 445-457. doi: 10.3354/aei00321

Oppedal, F., Samsing, F., Dempster, T., Wright, D. W., Bui, S., and Stien, L. H. (2017). Sea lice infestation levels decrease with deeper 'snorkel' barriers in Atlantic salmon sea-cages. Pest Manag. Sci. 73, 1935-1943. doi: 10.1002/ps. 4560

Piasecki, W., and MacKinnon, B. M. (1995). Life cycle of a sea louse, Caligus elongatus von Nordmann, 1832 (Copepoda, Siphonostomatoida, Caligidae). Can. J. Zool. 73, 74-82. doi: 10.1139/z95-009

Pike, A. W., Mordue Luntz, A. J., and Ritchie, G. (2006). "The development of Caligus elongatus nordmann from hatching to copepodid in relation to temperature," in Pathogens of Wild And Farmed Fish: Sea Lice, Vol. 4, eds G. A. Boxshall and D. Defaye (Chichester: Ellis Horwood Limited), 51-61.

Pike, A. W., and Wadsworth, S. L. (1999). Sealice on salmonids: their biology and control. Adv. Parasitol. 44, 233-237. doi: 10.1016/s0065-308x(08) 60233-x

Powell, A., Treasurer, J. W., Pooley, C. L., Keay, A. J., Lloyd, R., Imsland, A. K., et al. (2018). Use of lumpfish for sea-lice control in salmon farming: challenges and opportunities. Rev. Aquac. 10, 683-702. doi: 10.1111/raq.12194

R Core Team (2019). R: A Language and Environment for Statistical Computing. Vienna: R Foundation for Statistical Computing.

Reiczigel, J., Marozzi, M., Fabian, I., and Rozsa, L. (2019). Biostatistics for parasitologists - a primer to quantitative parasitology. Trends Parasitol. 35, 277-281. doi: 10.1016/j.pt.2019.01.003

Rozsa, L., Reiczigel, J., and Majoros, G. (2000). Quantifying parasites in samples of hosts. J. Parasitol. 86, 228-232. doi: 10.1645/0022-3395(2000)086[0228: qpisoh]2.0.co;2
Salama, N. K., Murray, A. G., and Rabe, B. (2016). Simulated environmental transport distances of Lepeophtheirus salmonis in Loch Linnhe, Scotland, for informing aquaculture area management structures. J. Fish Dis. 39, 419-428. doi: $10.1111 /$ jfd.12375

Salvatore, M. (2019). rcompanion: Functions to Support Extension Education Program Evaluation Cran Repos. Available online at: http://rcompanion.org/ (accessed November 25, 2019).

Samsing, F., Johnsen, I., Stien, L. H., Oppedal, F., Albretsen, J., Asplin, L., et al. (2016). Predicting the effectiveness of depth-based technologies to prevent salmon lice infection using a dispersal model. Prevent. Vet. Med. 129, 48-57. doi: $10.1016 /$ j.prevetmed.2016.05.010

Schram, T. A. (2000). The egg string attachment mechanism in salmon lice Lepeophtheirus salmonis (Copepoda : Caligidae). Contribut. Zool. 69, 21-29. doi: 10.1163/18759866-0690102002

Schram, T. A. (2004). Practical identification of pelagic sea lice larvae. J. Mar. Biol. Assoc. U. K. 84, 103-110. doi: 10.1017/s0025315404008963h

Skarð̆hamar, J., Nilsen Fagerli, M., Reigstad, M., Sandvik, A. D., and Bjørn, P. A. (2019). Sampling planktonic salmon lice in Norwegian fjords. Aquac. Environ. Interact. 11, 701-715. doi: 10.3354/aei00342

Stien, L. H., Dempster, T., Bui, S., Glaropoulos, A., Fosseidengen, J. E., Wright, D. W., et al. (2016). 'Snorkel' sea lice barrier technology reduces sea lice loads on harvest-sized Atlantic salmon with minimal welfare impacts. Aquaculture 458, 29-37. doi: 10.1016/j.aquaculture.2016.02.014

Stien, L. H., Lind, M. B., Oppedal, F., Wright, D. W., and Seternes, T. (2018). Skirts on salmon production cages reduced salmon lice infestations without affecting fish welfare. Aquaculture 490, 281-287. doi: 10.1016/j.aquaculture.2018. 02.045

Stien, L. H., Nilsson, J., Hevroy, E. M., Oppedal, F., Kristiansen, T. S., Lien, A. M., et al. (2012). Skirt around a salmon sea cage to reduce infestation of salmon lice resulted in low oxygen levels. Aquac. Eng. 51, 21-25. doi: 10.1016/j.aquaeng. 2012.06.002

Swift, M. R., Fredriksson, D. W., Unrein, A., Fullertonc, B., Patursson, O., and Baldwin, K. (2006). Drag force acting on biofouled net panels. Aquac. Eng. 35, 292-299. doi: 10.1016/j.aquaeng.2006.03.002

Thompson, C. (2020). A finne lusa i høystakken [Finding the louse in the haystack]. Paper Presented at Havbruk 2020, (Norway: Norwegian Seafood Research Fund).

Thorvaldsen, T., Frank, K., and Sunde, L. M. (2019). Practices to obtain lice counts at Norwegian salmon farms: status and possible implications for representativity. Aquac. Environ. Interact. 11, 393-404. doi: 10.3354/aei00323

Tucker, C. S., Sommerville, C., and Wootten, R. (2000). An investigation into the larval energetics and settlement of the sea louse, Lepeophtheirus salmonis, an ectoparasitic copepod of Atlantic salmon, Salmo salar. Fish Pathol. 35, 137-143. doi: $10.3147 /$ jsfp. 35.137

Warnes, G. R., Bolker, B., Lumley, T., and Johnson, R. C. (2018). gmodels: Various R Programming Tools for Model Fitting. Available online at: https://rdrr.io/cran/ gmodels/ (accessed November 25, 2019).

Wright, D. W., Stien, L. H., Dempster, T., Vagseth, T., Nola, V., Fosseidengen, J. E., et al. (2017). 'Snorkel' lice barrier technology reduced two co- occurring parasites, the salmon louse (Lepeophtheirus salmonis) and the amoebic gill disease causing agent (Neoparamoeba perurans), in commercial salmon seacages. Prevent. Vet. Med. 140, 97-105. doi: 10.1016/j.prevetmed.2017.03.002

Conflict of Interest: The authors declare that the research was conducted in the absence of any commercial or financial relationships that could be construed as a potential conflict of interest.

Copyright (c) 2020 Jevne, Øvrelid, Hagemann, Bloecher, Steinhovden, Båtnes, Olsen and Reitan. This is an open-access article distributed under the terms of the Creative Commons Attribution License (CC BY). The use, distribution or reproduction in other forums is permitted, provided the original author(s) and the copyright owner(s) are credited and that the original publication in this journal is cited, in accordance with accepted academic practice. No use, distribution or reproduction is permitted which does not comply with these terms. 